\title{
Residual sleepiness in patients with OSA on CPAP
}

\section{To the Editors:}

PEPIN et al. [1] recently published a very interesting study of residual excessive sleepiness (RES) in 502 patients with obstructive sleep apnoea treated successfully with continuous positive airway pressure (CPAP). They concluded that a significant percentage (about $6-12 \%$, depending on inclusion criteria) had RES. They concluded that, since about 230,000 French patients are on CPAP, a minimum of 13,800 might suffer from RES, as defined by an Epworth Sleepiness Score $(E S S) \geqslant 11$. In 2007, we looked at the same issue in 572 patients with OSA from the Oxford Sleep Clinic [2], but compared them with a community-based sample of 525 control subjects [3]. What was striking, was that there was no difference between the patients and the control subjects, implying that patients on CPAP had no greater a proportion with RES than the general population. This was not to say that the subjects in the control

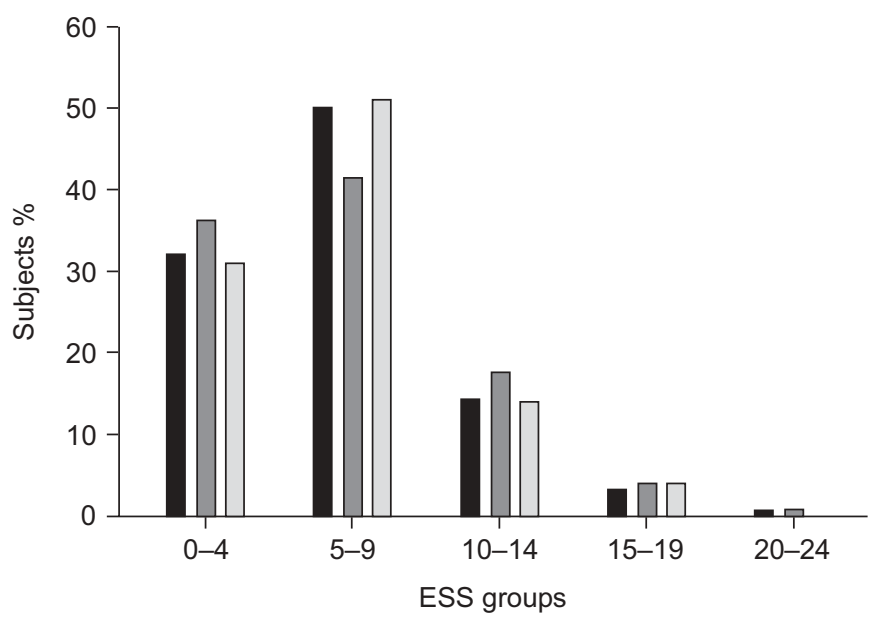

FIGURE 1. Percentage of subjects categorised in each Epworth Sleepiness Score (ESS) quintile. Data are for control subjects ( $\square,[3])$ and patients receiving continuous positive airway pressure (CPAP) treatment ( $\square$ from [2], and $₫$ from [1]) population were normal, there would have been subjects with a variety of sleep disorders on statistical grounds alone. The point we felt important was that the patients on CPAP appeared no different, thus arguing against there being any specific residual problem in patients with OSA receiving successful CPAP treatment. I have redrawn the graph (\% of subjects versus ESS quintile) from our 2007 paper and included as a third column the raw data from PEPIN et al. [1] (fig. 1). Again, what is striking is that the ESS distribution from the French patients on CPAP is virtually identical to the Oxford groups of both CPAP patients and control subjects. The purpose of this correspondence is again to question whether sleepiness in successfully treated patients with OSA is any different to "normal".

\section{J.R. Stradling}

Oxford Centre for Respiratory Medicine, Churchill Hospital, Oxford, OX3 7LJ, UK.

Correspondence: J.R. Stradling, Oxford Centre for Respiratory Medicine, Churchill Hospital, Oxford, OX3 7LJ, UK. E-mail: john.stradling@orh.nhs.uk

Statement of Interest: None declared

\section{REFERENCES}

1 Pepin JL, Viot-Blanc V, Escourrou P, et al. Prevalence of residual excessive sleepiness in CPAP-treated sleep apnoea patients: the French multicentre study. Eur Respir J 2009; 33: 1062-1067.

2 Stradling JR, Smith D, Crosby J. Post-CPAP sleepiness-a specific syndrome? J Sleep Res 2007; 16: 436-438.

3 Stradling JR, Barbour C, Glennon J, et al. Prevalence of sleepiness and its relation to autonomic evidence of arousals and increased inspiratory effort in a community based population of men and women. J Sleep Res 2000; 9: 381-388.

\section{Is there a metabolic effect of continuous positive airway pressure in sleep apnoea? Adherence should not be underestimated}

\section{To the Editors:}

We read with great interest the excellent article by LÉvY et al. [1], which was published recently in the European Respiratory Journal. The authors conclude that continuous positive airway pressure (CPAP) treatment has little or no effect on the metabolic status of obese obstructive sleep apnoea (OSA) patients, presumably due to the major impact of visceral obesity [1].

While we agree on most issues covered in this article, we would also like to emphasise the role of adherence to CPAP 